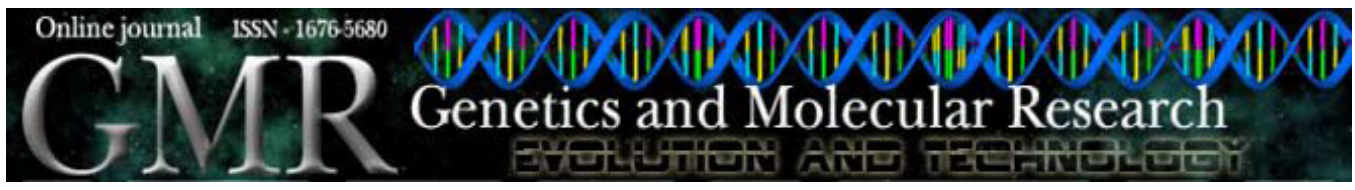

\title{
Effects of Thai black sticky rice extract on oxidative stress and lipid metabolism gene expression in HepG2 cells
}

\author{
W. Sangkitikomol ${ }^{1}$, T. Tencomnao ${ }^{1}$ and A. Rocejanasaroj ${ }^{2}$ \\ ${ }^{1}$ Department of Clinical Chemistry, Center for Excellence in Omics-Nano \\ Medical Technology Development Project, Faculty of Allied Health Sciences, \\ Chulalongkorn University, Bangkok, Thailand \\ ${ }^{2}$ Graduate Program in Clinical Biochemistry and Molecular Medicine, \\ Department of Clinical Chemistry, Faculty of Allied Health Sciences, \\ Chulalongkorn University, Bangkok, Thailand
}

Corresponding author: W. Sangkitikomol

E-mail: warin.s@chula.ac.th

Genet. Mol. Res. 9 (4): 2086-2095 (2010)

Received May 21, 2010

Accepted July 24, 2010

Published October 19, 2010

DOI 10.4238/vol9-4gmr912

\begin{abstract}
Anthocyanins, which are found in some food, including Thai black sticky rice, are reported to have health-promoting properties. Oxidative stress plays a major role in the pathogenesis of many degenerative diseases induced by free radicals, such as cardiovascular disease, stroke and cancer. We evaluated the anthocyanin-rich extract (ARE) from Thai black sticky rice for antioxidative and antihyperlipidemic effects on HepG2 cells. Cell viability was investigated with the neutral red assay and the MTT assay, and oxidative stress was determined by the DCFH-DA assay. RT-PCR was used to evaluate the effect of ARE on LDLR, HMG-CoAR, PPAR $(\alpha 1, \gamma)$ and LXR $\alpha$ gene expression. We found that ARE at high doses $(\geq 800 \mathrm{mg} / \mathrm{L})$ induces cytotoxicity. However, at $600-1000 \mathrm{mg} / \mathrm{L}$ it reduced intracellular oxidative stress $(\mathrm{P}<0.05)$ in a dose-dependent manner, and at $200 \mathrm{mg} / \mathrm{L}$
\end{abstract}


it significantly enhanced the expression of the LDLR gene in HepG2 cells. We concluded that ARE can be beneficial for health promotion by reducing oxidative stress and enhancing LDL clearance, regulating LDLR production on the cell surface membrane, thereby maintaining lipid homeostasis.

Key words: Thai black sticky rice; Antioxidant; Oxidative stress; Lipid metabolism genes

\section{INTRODUCTION}

Natural products have been used for therapeutic purposes in traditional and folk medicine. Black rice (Oryza sativa L. indica), an enriched source of flavonoids, is widely used for therapeutic purposes and is gradually becoming popular in Thailand. Anthocyanins are found more in black sticky rice than in red rice or black rice (Sangkitikomol et al., 2008). Oxidative stress plays a major role in the pathogenesis of many degenerative diseases induced by free radicals such as cardiovascular disease, stroke and cancer, and in aging as well (Halliwell and Gutteridge, 2001; Galati and O'Brien, 2004). Experimental and clinical studies have reported a positive correlation between cardiovascular health status and the consumption of black rice and/or black rice pigments. Supplementation of black rice pigments has been shown to improve the antioxidant and anti-inflammatory status in patients with coronary heart disease (Wang et al., 2007), reduced oxidative stress and inflammation, improved plasma lipid levels and alleviated atherosclerotic lesions in animal models (Auger et al., 2002). Black rice pigments attenuate atherosclerotic plaque formation in rabbits (Ling et al., 2002) and in apolipoprotein E-deficient mice (Xia M et al., 2003; Xia X et al., 2006). Some flavonoids have been found to act differently depending on their doses, particularly a cytoprotective effect at low doses, while a cytotoxic effect and induction of DNA strand breaks at high doses (Wätjen et al., 2005). The regulation of cholesterol homeostasis is associated with low-density lipoprotein receptor (LDLR), a membrane receptor, for removal of LDL from the blood circulation, which contributes to lower plasma cholesterol levels. The activity of 3-hydroxy-3-methyl-glutaryl-CoA reductase (HMG-CoAR), the rate controlling enzyme, is expressed to synthesize cholesterol for cholesterol homeostasis inside the cells. The peroxisome proliferator-activated receptors $[\operatorname{PPAR}(\alpha 1, \gamma)]$ and the liver X receptor $\alpha$ $(\mathrm{LXR} \alpha)$, nuclear membrane receptors, are important regulators of cholesterol, fatty acid, and glucose homeostasis (Powell and Kroon, 1994; Bays and Stein, 2003; Kaul et al., 2005).

The present investigation aimed to determine the dose-response of anthocyanin-rich extract (ARE) from Thai black sticky rice against oxidative stress and the mRNA expression of lipid metabolism genes including LDLR, HMG-CoAR, PPAR $(\alpha 1, \gamma)$, and LXR $\alpha$ in HepG2 cells.

\section{MATERIAL AND METHODS}

\section{Chemicals}

Neutral red dye, 3-(4,5-dimethylthiazol-2-yl)-2,5-diphenyl tetrazolium bromide (MTT), ethidium bromide and 2',7'-dichlorofluorescein diacetate (DCFH-DA) were pur- 
chased from Sigma-Aldrich, St. Louis, MO, USA. Dulbecco's modified Eagle's medium (DMEM, with $4 \mathrm{mM}$ glutamine, $4500 \mathrm{mg} / \mathrm{L}$ glucose without sodium pyruvate), fetal bovine serum (FBS), 1X EDTA-trypsin $0.25 \%$ were obtained from Thermo Scientific HyClone, Logan, UT, USA. TRI reagent was purchased from Molecular Research Center Inc., Cincinnati, OH, USA. RNase inhibitor, 100-bp DNA ladder, deoxyribonuclease I and primers were purchased from Bio Basic Inc., Ontario, Canada. M-MuLV Reverse transcriptase was purchased from Finnzymes Inc., Espoo, Finland. Amphotericin B (Fungizone) and penicillin-streptomycin solutions came from Biochrom AG, Berlin, Germany. All other basic reagents were of analytical grade.

\section{Preparation of ARE from Thai black sticky rice}

ARE fraction was prepared from Thai black sticky rice that was previously shown by our group to possess certain characteristics: including total antioxidant properties, $1368.34 \pm$ $41.27 \mathrm{mM}$ Trolox equivalents/kg dry mass (ORAC - fluorescein assay); total phenolic compounds, $922.03 \pm 9.42 \mathrm{mM}$ gallic acid equivalents/kg dry mass (Folin - Ciocalteu assay), and anthocyanins, $218.97 \pm 1.82 \mathrm{mM}$ catechin equivalents/kg dry mass (vanillin assay) (Sangkitikomol et al., 2008). In brief, 100 g black sticky rice was milled and extracted in $2000 \mathrm{~mL}$ $80 \%$ methanol in water. This crude extract was refluxed at $75-78^{\circ} \mathrm{C}$ for $3 \mathrm{~h}$, shaken in an ultrasonic bath for $30 \mathrm{~min}$, cooled, and stored in the dark at $4-8^{\circ} \mathrm{C}$ for 7 days, after which the sediment was removed by centrifugation at $3000 \mathrm{rpm}$ for $15 \mathrm{~min}$. The extract was concentrated using a vacuum rotary evaporator at $50^{\circ} \mathrm{C}$ and freeze-dried giving a yield of dried extract of $0.5 \mathrm{~g}$. This dried extract was kept in a deep freezer at $-80^{\circ} \mathrm{C}$ until used.

\section{Preparation of HepG2 cells and biological analysis}

The HepG2 cell line was a generous gift from Assoc. Prof. Dr. Parvapan Bhattarakosol, Faculty of Medicine, Chulalongkorn University, Bangkok, Thailand. HepG2 cells were grown in DMEM supplemented with $4 \mathrm{mM}$ glutamine, $4.5 \mathrm{~g} / \mathrm{L}$ glucose, $10 \%$ heat-inactivated FBS, $0.1 \%$ amphotericin B (Fungizone) and $1 \%$ penicillin-streptomycin, and they were maintained at $37^{\circ} \mathrm{C}$ in a humidified atmosphere at $5 \% \mathrm{CO}_{2}$. The culture medium was changed twice a week, and the cells were subcultured once a week. The cells were seeded at a density of 1 x $10^{6}$ cells/well in 6-well plates with a final volume of $5 \mathrm{~mL} /$ well for reverse transcriptasepolymerase chain reaction (RT-PCR) assay and $1 \times 10^{4}$ cells/well in 96-well plates with a final volume of $0.2 \mathrm{~mL} /$ well for oxidative stress (DCFH-DA assay) and cell viability test using the neutral red (NR) assay and MTT assay, respectively.

\section{Neutral red assay}

HepG2 cell viability was assessed by using the NR assay as previously described (Zhang et al., 1990) with some modifications. Briefly, following the cell treatments, HepG2 cells were exposed to $100 \mu \mathrm{L}$ NR solution ( $4 \mathrm{mg} / \mathrm{mL}$ in phosphate-buffered saline (PBS), $\mathrm{pH}$ 7.5 ) for $3 \mathrm{~h}$ at $37^{\circ} \mathrm{C}$ to allow the lysosomes of viable cells to take up the vital stain (NR). This process requires metabolically active cells. Failure to take up NR, therefore, indicates that those cells have suffered damage. The cultures were rapidly washed with $1 \%$ formaldehyde- 
$1 \%$ calcium chloride to remove the excess NR. A mixture of $1 \%$ acetic acid- $50 \%$ ethanol was added to the HepG2 cells to extract the NR from these cells at room temperature for $30 \mathrm{~min}$. The supernatants were transferred to 96-well plates, and the absorbance at $550 \mathrm{~nm}$ was then measured. The $\%$ cell survival was calculated according to the following formula: \% cell survival $=[($ absorbance of treatment group - blank $) /($ absorbance of control group - blank $)] \mathrm{x}$ 100. This method was carried out using VICTOR ${ }^{2}$ Multilabel Counter (Perkin Elmer Life and Analytical Sciences, Finland).

\section{MTT assay}

HepG2 cell viability was assessed using the MTT assay as previously described (Twentyman and Luscombe, 1987) with some modifications. The assay is dependent on the ability of viable cells to metabolize MTT, a water-soluble tetrazolium salt (yellow color), by mitochondrial succinate dehydrogenase into a water-insoluble formazan product (dark purple color). Briefly, following the cell treatments, HepG2 cells in each well of the 96-well plate were subjected to MTT assay by mixing with $20 \mu \mathrm{L}$ MTT solution [5 $\mathrm{mg} / \mathrm{mL}$ in PBS], and incubation at $37^{\circ} \mathrm{C}$ in $5 \% \mathrm{CO}_{2}$ incubator for $4 \mathrm{~h}$. Subsequently, the medium was removed, $150 \mu \mathrm{L} 50 \%$ ethanol in DMSO was added to each well to dissolve the formazan product, and the absorbance was measured at $550 \mathrm{~nm}$. Since the reduction of MTT can occur in metabolically active cells, the level of activity is a measure of the viability of the cells. The \% cellular activity was calculated according to the following formula: \% cellular activity $=[($ absorbance of treatment group - blank $) /($ absorbance of control group - blank)] x 100. This method was carried out using VICTOR ${ }^{2}$ Multilabel Counter (Perkin Elmer Life and Analytical Sciences).

\section{DCFH-DA assay}

DCFH-DA has been used as a substrate for measuring intracellular oxidant production in HepG2 cells (Wang and Joseph, 1999). Briefly, following the cell treatments, HepG2 cells were centrifuged for $10 \mathrm{~min}$ at $2500 \mathrm{rpm}$ and then washed three times with PBS, $\mathrm{pH}$ 7.4. The cells were mixed with $100 \mu \mathrm{L}$ of $100 \mu \mathrm{M}$ DCFH-DA in PBS, and incubated for $90 \mathrm{~min}$ at $37^{\circ} \mathrm{C}$ in a humidified $5 \% \mathrm{CO}_{2}$ atmosphere. The non-ionic, non-polar DCFH-DA crosses cell membranes and is hydrolyzed by intracellular esterases to non-fluorescent dichlorofluorescin (DCFH). In the presence of reactive oxygen species (ROS) inside the cells, DCFH is oxidized to highly fluorescent, dichlorofluorescein (DCF). The cells were centrifuged for $10 \mathrm{~min}$ at 2500 $\mathrm{rpm}$ and then washed three times with PBS, pH 7.4. The fluorescent measurement was monitored using VICTOR ${ }^{2}$ Multilabel Counter (Perkin Elmer Life and Analytical Sciences) at 485 and $535 \mathrm{~nm}$ for excitation and emission, respectively. Therefore, the intracellular DCF fluorescence can be used as an index to quantify the overall oxidative stress in the cells. The $\%$ cellular oxidative stress was calculated according to the following formula: \% cellular oxidative stress $=[($ fluorescence of treatment group - blank) / (fluorescence of control group - blank) $] \times 100$.

\section{Detection of lipid metabolism gene expression using RT-PCR method}

In this investigation, mRNA expression of lipid metabolism genes including LDLR, HMG- 
CoAR, PPAR $(\alpha 1, \alpha 2, \gamma)$, and LXR $\alpha$ in HepG2 cells was detected using the RT-PCR method according to previous reports with minor modification (Powell and Kroon, 1994; Kaul et al., 2005). Briefly, 1 x $10^{6}$ cells HepG2 suspended in DMEM in 6-well plates were mixed with ARE (0 to $600 \mathrm{mg} / \mathrm{L}$ with $0=$ control). After incubation for $29 \mathrm{~h}$ at $37^{\circ} \mathrm{C}$ in a humidified $5 \% \mathrm{CO}_{2}$ atmosphere, total RNA was isolated from HepG2 cells using the TRI reagent following the manufacturer protocol. Purity and quantity of total RNA were determined using agarose gel electrophoresis and a spectrophotometer. The synthesis of cDNA was performed using $2 \mu \mathrm{g}$ total RNA, random primers and M-MuLV-reverse transcriptase at $42^{\circ} \mathrm{C}$ for $1 \mathrm{~h}$. Subsequently, PCR was carried out using specific primer pairs in order to generate PCR products, which were 258-bp LDLR (sense 5'-CAATGTCTCACCAAGCTCTG-3' and antisense 5'-TCTGTCTCGAGGGGTAGCTG-3'), 247-bp HMG-CoAR (sense 5'-CTTGTGTG TCCTTGGTATTAGAGCTT-3' and antisense 5'-TTATCATCTTGACCCTCTGAGTTACAG-3'), 728-bp PPAR $\alpha 1$ and 525-bp PPAR $\alpha 2$ (sense 5'-AGTCTCCCAGTGGAGCATTGAACA-3' and antisense 5'-ATACGCTACCAGCATCCCGTCTTT-3'),434-bpPPAR $\gamma$ (sense 5'-AGCCTCATGA AGAGCCTTCCAACT-3' and antisense 5'-TGTCTTTCCTGTCAAGATCGCCCT-3'), 818-bp LXR $\alpha$ (sense 5'-AACCCACAGAGATCCGTCCACAAA-3' and antisense 5'-ATTCATGGCC CTGGAGAACTCGAA-3') and 656-bp $\beta$-actin (sense 5'-ACGGGTCACCCACACTGTGC-3' and antisense 5'-CTAGAAGCATTTGCGGTGGACGATG-3'). RT-PCR products along with a DNA ladder were electrophoresed on an agarose gel and visualized by ethidium bromide staining using a gel documentation system. For data analysis, the GeneTools software 3.08 (SynGene, Cambridge, UK) was utilized. The expression of genes was normalized to that of $\beta$-actin, and data for treatment with each ARE concentration were presented as fold change in normalized mRNA expression relative to that of no ARE treatment (control).

\section{Statistical analysis}

Statistically significant differences between control and exposed groups were evaluated by one-way ANOVA (SPSS version 17.0 for Windows) and the Student $t$-test. P value was two-tailed, and $\mathrm{P}<0.05$ was considered to be statistically significant when comparing the data sets.

\section{RESULTS}

\section{Effect of ARE on cell survival and oxidative stress in HepG2 cells}

According to the HepG2 viability tests, ARE in the $800-1000 \mathrm{mg} / \mathrm{L}$ concentration range significantly reduced the number of living cells (neutral red assay, Figure 1A), while the $100-400 \mathrm{mg} / \mathrm{L}$ concentration range significantly increased the activity of cellular metabolizing enzymes (MTT assay, Figure 1B), upon incubation for $58 \mathrm{~h}(\mathrm{P}<0.05)$. In the DCFH-DA assay, HepG2 cells treated with $\geq 600 \mathrm{mg} / \mathrm{L}$ ARE significantly reduced oxidative stress $(\mathrm{P}<0.05)$ in a dose-dependent manner (Figure 1C).

\section{The effect of ARE on lipid metabolism gene expression in HepG2 cells}

With regard to the mRNA expression of lipid metabolism genes (Figures 2 and 3), 200 $\mathrm{mg} / \mathrm{L}$ ARE significantly enhanced the expression of LDLR gene in HepG2 cells $(\mathrm{P}<0.05)$, 
whereas ARE at higher concentrations $(400-600 \mathrm{mg} / \mathrm{L})$ resulted in lower levels of LDLR mRNA as compared to those for $200 \mathrm{mg} / \mathrm{L}$ ARE. As far as the mRNA expression of PPAR $\gamma$ gene in response to ARE is concerned, its expression was similar to that of LDLR gene. The difference in mRNA expression in response to various concentrations of ARE was not observed for the HMG-CoAR, PPAR $\alpha 1$ and LXR $\alpha$ genes. The expression of PPAR $\alpha 2$ mRNA detected simultaneously when using the PCR primer pair for PPAR $\alpha 1$ mRNA was not of interest in our present study since it is known to be an inactive isoform.

\section{DISCUSSION}
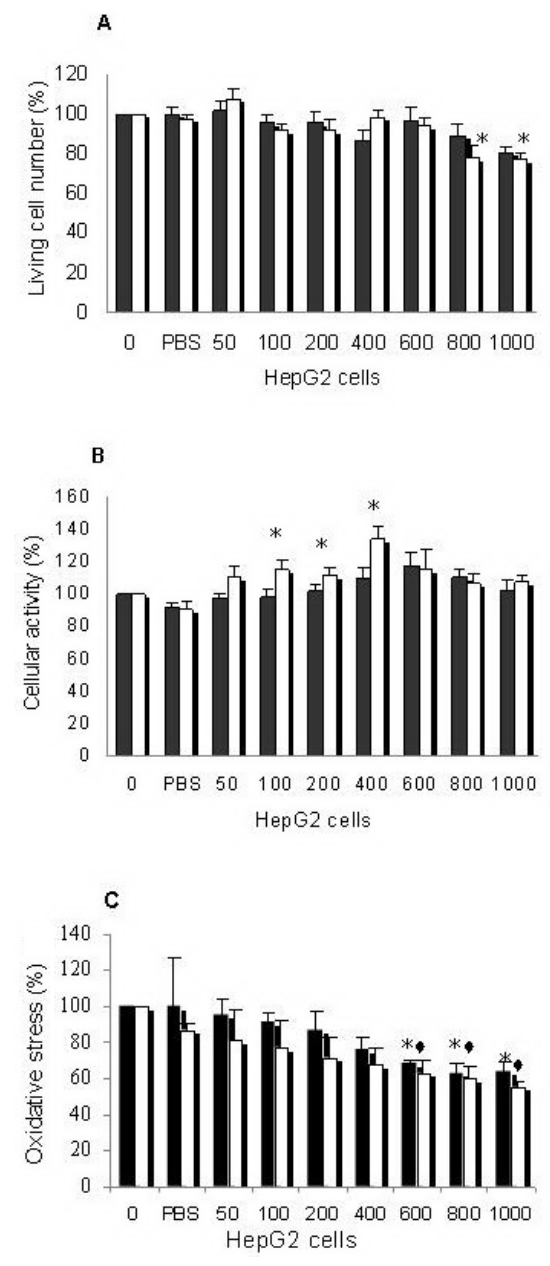

Figure 1. The effect of anthocyanin-rich extract (ARE) on cytotoxicity and oxidative stress of HepG2 cells. HepG2 cells were incubated with different concentrations of ARE $(0-1000 \mathrm{mg} / \mathrm{L})$ at the end of experimental periods of 29 $\mathrm{h}$ (filled columns) and $58 \mathrm{~h}$ (open columns). A. The number of living HepG2 cells was determined using neutral red assay B. The cellular activity of living HepG2 cells was assessed using the MTT assay. C. The oxidative stress in HepG2 cells was evaluated using the DCFH-DA assay. Values are reported as means with their standard error of the mean $(\mathrm{SEM})$ depicted by vertical bars. All experiments were performed in triplicate $(\mathrm{N}=3)$. $\mathrm{PBS}=$ phosphatebuffered saline. ${ }^{*,} \mathrm{P}<0.05$ for significant change as compared to control (no treatment). 

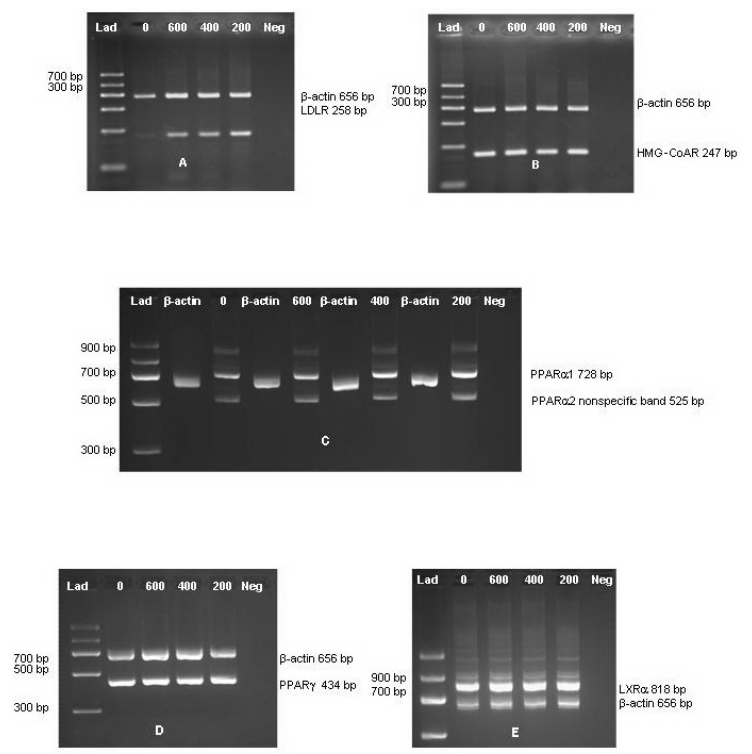

Figure 2. Effect of anthocyanin-rich extract (ARE) on mRNA expression of certain lipid metabolism genes in HepG2 cells in a dose-dependent manner as determined using the RT-PCR approach. Representative agarose gel photographs showed RT-PCR products corresponding to expected sizes of the lipid metabolism genes studied. A. LDLR. B. HMG-CoAR. C. PPAR $\alpha 1$ and PPAR $\alpha 2$ nonspecific band (isoform). D. PPAR $\gamma$. E. LXR $\alpha$. The mRNA expression of $\beta$-actin gene was used for normalization. HepG2 cells were treated with ARE ( 0 to $600 \mathrm{mg} / \mathrm{L} ; 0=$ control). LDLR = low-density lipoprotein receptor; HMG-CoAR = 3-hydroxy-3-methyl-glutaryl-CoA reductase; $\mathrm{PPAR}=$ proliferator-activated receptors; $\mathrm{LXR} \alpha=$ liver $\mathrm{X}$ receptor $\alpha$.

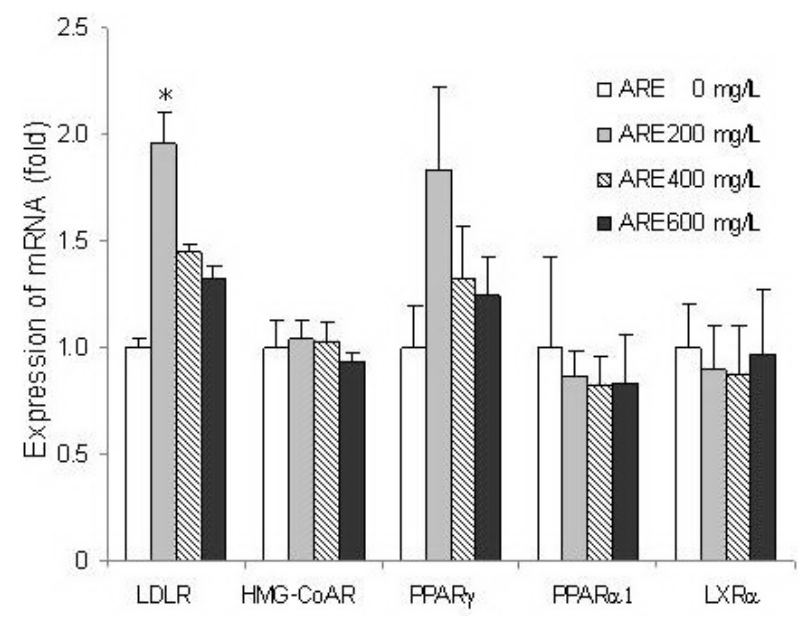

Figure 3. The mRNA expression of lipid metabolism genes (LDLR, HMG-CoAR, PPAR $\alpha 1$, PPAR $\gamma$, and LXR $\alpha$ ) in HepG2 cells treated with varying concentrations of anthocyanin-rich extract (ARE, $0-600 \mathrm{mg} / \mathrm{L} ; 0=$ control) was evaluated using RT-PCR. The mRNA expression of the genes studied was normalized to that of the $\beta$-actin gene. Values derived from normalized band intensities are means with their standard error of the mean (SEM) depicted by vertical bars. All experiments were performed in triplicate $(\mathrm{N}=3)$. $* \mathrm{P}<0.05$ for significant change in normalized gene expression as compared to control. For abbreviations, see legend to Figure 2. 
ARE enhanced cellular enzymatic activities, as shown in the MTT assay. Oxidative stress-induced ROS production detected with DCFH-DA was significantly decreased by ARE in a dose-dependent manner. Based on this particular experiment, we found that ARE in the $600-1000 \mathrm{mg} / \mathrm{L}$ concentration range reduced oxidative stress in HepG2 cells in a dose-dependent manner. Therefore, the toxic effect of ARE $(\geq 800 \mathrm{mg} / \mathrm{L})$ on HepG2 cells may be due to its inhibitory or stimulatory actions via kinase signaling pathways, which are likely to affect cellular function by altering the phosphorylation state of target molecules and by modulating gene expression (Williams et al., 2004). These findings suggest that ARE at high concentrations may not be appropriate for health-promoting purposes. Other studies indicated that lower concentrations of flavonoids (nM to low $\mu \mathrm{M}$ ) could lead to antioxidant response element-mediated gene expression, including that of phase II detoxifying enzymes. In contrast, higher concentrations of flavonoids may sustain the activation of mitogen-activated protein kinases or stress-activated protein kinases, which could induce apoptosis (Chen et al, 2000; Kong et al, 2000). Many reports have described the adverse actions of flavonoids at the cellular level. For example, due to the toxic effects of flavonoids at high concentrations, several lines of evidence have reported induction of DNA strand breaks when using such flavonoids as epigallocatechin-3-gallate (Tian et al., 2007), quercetin (Beatty et al., 2000), and kaempferol (Niering et al., 2005). Other natural products used for lowering lipids, such as phytoestrogens, estrogens and soy proteins have been shown to have the ability to increase hepatic LDLR activity (Owen et al., 2004).

Analyzing the effect of ARE on lipid metabolism gene expression using the RT-PCR method, ARE significantly induced the expression of LDLR gene in HepG2 cells in a unique dosedependent manner. ARE at 600, 400 and $200 \mathrm{mg} / \mathrm{L}$ progressively increased LDLR gene expression, respectively corresponding to 1.3-, 1.5- and 2-fold higher levels relative to control (untreated HepG2 cells). Also, a similar trend was true for PPAR $\gamma$ gene, since its expression was respectively 1.2-, 1.3- and 1.8-fold higher than that of control. ARE exhibits this particular biological activity similar to that of $\alpha$-tocopherol, which has been demonstrated to function in a concentration-dependent fashion with a biphasic 'up then down' effect on LDLR in HepG2 cells (Pal et al., 2003). In particular, at low levels of $\alpha$-tocopherol (up to $50 \mu \mathrm{M}$ ), LDLR binding activity, protein and mRNA were progressively induced to maximum levels, while they gradually decreased to baseline levels at concentrations higher than $50 \mu \mathrm{M}$. PPAR $\gamma$ is a ligand-activated nuclear receptor with essential roles in adipogenesis, glucose and lipid homeostasis, and inflammatory responses. These roles may be considered possible mechanisms for reducing the risk of cardiovascular diseases (Xu and $\mathrm{Li}, 2008)$. Since the present study showed that ARE induces the expression of LDLR and PPAR $\gamma$ genes, these particular genes may regulate energy metabolism in the HepG2 cells. According to microarray analysis, gene expression patterns of liver and skeletal muscles were significantly affected by treatment with anthocyanins (Lefevre et al., 2008). In particular, the first set discovered included down-regulated pathways in both muscle and liver involved in cellular defense (inflammatory response genes and oxidative stress genes), whereas another set included hepatic genes involved in energy metabolism in the liver, with major metabolic pathways down-regulated such as the TCA cycle, fatty acid $\beta$-oxidation, and cholesterol biosynthesis.

In conclusion, ARE showed protective effects at low concentrations $(\leq 600 \mathrm{mg} / \mathrm{L})$, while it exhibited a toxic effect at high concentrations $(\geq 800 \mathrm{mg} / \mathrm{L})$. At the molecular level, ARE at a low concentration $(200 \mathrm{mg} / \mathrm{L})$ regulated the production of LDLR on cell surface membranes, thereby maintaining lipid homeostasis. Taken together, these results support the 
notion that ARE is biologically active in a dose-dependent manner.

\section{ACKNOWLEDGMENTS}

Research supported by the Faculty of Allied Health Sciences, Chulalongkorn University Centenary Academic Development Project and Graduate Research Grant, Chulalongkorn University. The authors gratefully acknowledge the generous gift of the HepG2 cells from Assoc. Prof. Dr. Parvapan Bhattarakosol.

\section{REFERENCES}

Auger C, Caporiccio B, Landrault N, Teissedre PL, et al. (2002). Red wine phenolic compounds reduce plasma lipids and apolipoprotein B and prevent early aortic atherosclerosis in hypercholesterolemic golden Syrian hamsters (Mesocricetus auratus). J. Nutr. 132: 1207-1213.

Bays H and Stein EA (2003). Pharmacotherapy for dyslipidaemia - current therapies and future agents. Expert. Opin. Pharmacother. 4: 1901-1938.

Beatty ER, O'Reilly JD, England TG, McAnlis GT, et al. (2000). Effect of dietary quercetin on oxidative DNA damage in healthy human subjects. Br. J. Nutr. 84: 919-925.

Chen C, Yu R, Owuor ED and Kong AN (2000). Activation of antioxidant-response element (ARE), mitogen-activated protein kinases (MAPKs) and caspases by major green tea polyphenol components during cell survival and death. Arch. Pharm. Res. 23: 605-612.

Galati G and O'Brien PJ (2004). Potential toxicity of flavonoids and other dietary phenolics: significance for their chemopreventive and anticancer properties. Free Radic. Biol. Med. 37: 287-303.

Halliwell B and Gutteridge JMC (2001). Free Radicals in Biology and Medicine. Oxford Science Publication, Thomson Press Ltd., India.

Kaul D, Shukla AR, Sikand K and Dhawan V (2005). Effect of herbal polyphenols on atherogenic transcriptome. Mol. Cell Biochem. 278: 177-184.

Kong AN, Yu R, Chen C, Mandlekar S, et al. (2000). Signal transduction events elicited by natural products: role of MAPK and caspase pathways in homeostatic response and induction of apoptosis. Arch. Pharm. Res. 23: 1-16.

LeFevre M, Wiles JE, Zhang X, Howard LR, et al. (2008). Gene expression microarray analysis of the effects of grape anthocyanins in mice: a test of a hypothesis-generating paradigm. Metabolism 57: S52-S57.

Ling WH, Wang LL and Ma J (2002). Supplementation of the black rice outer layer fraction to rabbits decreases atherosclerotic plaque formation and increases antioxidant status. J. Nutr. 132: 20-26.

Niering P, Michels G, Watjen W, Ohler S, et al. (2005). Protective and detrimental effects of kaempferol in rat H4IIE cells: implication of oxidative stress and apoptosis. Toxicol. Appl. Pharmacol. 209: 114-122.

Owen AJ, Roach PD and Abbey M (2004). Regulation of low-density lipoprotein receptor activity by estrogens and phytoestrogens in a HepG2 cell model. Ann. Nutr. Metab. 48: 269-275.

Pal S, Thomson AM, Bottema CD and Roach PD (2003). Alpha-tocopherol modulates the low density lipoprotein receptor of human HepG2 cells. Nutr. J. 2: 3 .

Powell EE and Kroon PA (1994). Low density lipoprotein receptor and 3-hydroxy-3-methylglutaryl coenzyme A reductase gene expression in human mononuclear leukocytes is regulated coordinately and parallels gene expression in human liver. J. Clin. Invest. 93: 2168-2174.

Sangkitikomol W, Tencomnao T and Rocejanasaroj A (2008). Comparison of total antioxidants of red rice, black rice and black sticky rice. J. Nut. Assoc. Thailand 43: 13-21.

Tian B, Sun Z, Xu Z and Hua Y (2007). Chemiluminescence analysis of the prooxidant and antioxidant effects of epigallocatechin-3-gallate. Asia Pac. J. Clin. Nutr. 16 (Suppl 1): 153-157.

Twentyman PR and Luscombe M (1987). A study of some variables in a tetrazolium dye (MTT) based assay for cell growth and chemosensitivity. Br. J. Cancer 56: 279-285.

Wang H and Joseph JA (1999). Quantifying cellular oxidative stress by dichlorofluorescein assay using microplate reader. Free Radic. Biol. Med. 27: 612-616.

Wang Q, Han P, Zhang M, Xia M, et al. (2007). Supplementation of black rice pigment fraction improves antioxidant and anti-inflammatory status in patients with coronary heart disease. Asia Pac. J. Clin. Nutr. 16 (Suppl 1): 295-301.

Wätjen W, Michels G, Steffan B, Niering P, et al. (2005). Low concentrations of flavonoids are protective in rat H4IIE 
cells whereas high concentrations cause DNA damage and apoptosis. J. Nutr. 135: 525-531.

Williams RJ, Spencer JP and Rice-Evans C (2004). Flavonoids: antioxidants or signalling molecules? Free Radic. Biol. Med. 36: 838-849.

Xia M, Ling WH, Ma J, Kitts DD, et al. (2003). Supplementation of diets with the black rice pigment fraction attenuates atherosclerotic plaque formation in apolipoprotein E deficient mice. J. Nutr. 133: 744-751.

Xia X, Ling W, Ma J, Xia M, et al. (2006). An anthocyanin-rich extract from black rice enhances atherosclerotic plaque stabilization in apolipoprotein E-deficient mice. J. Nutr. 136: 2220-2225.

Xu HE and Li Y (2008). Ligand-dependent and -independent regulation of PPAR gamma and orphan nuclear receptors. Sci. Signal. 1: e52.

Zhang SZ, Lipsky MM, Trump BF and Hsu IC (1990). Neutral red (NR) assay for cell viability and xenobiotic-induced cytotoxicity in primary cultures of human and rat hepatocytes. Cell Biol. Toxicol. 6: 219-234. 